\title{
Genèse et autofiction, sous la direction de Jean-Louis Jeannelle et Catherine Viollet
}

\section{Gabriella Bosco}

\section{Q OpenEdition \\ 1 Journals}

\section{Edizione digitale}

URL: http://journals.openedition.org/studifrancesi/9722

DOI: $10.4000 /$ studifrancesi.9722

ISSN: 2421-5856

\section{Editore}

Rosenberg \& Sellier

\section{Edizione cartacea}

Data di pubblicazione: 1 décembre 2007

Paginazione: $712-713$

ISSN: 0039-2944

\section{Notizia bibliografica digitale}

Gabriella Bosco, «Genèse et autofiction, sous la direction de Jean-Louis Jeannelle et Catherine Viollet», Studi Francesi [Online], 153 (LI | III) | 2007, online dal 30 novembre 2015, consultato il 12 janvier 2021. URL: http://journals.openedition.org/studifrancesi/9722 ; DOI: https://doi.org/10.4000/studifrancesi. 9722

Questo documento è stato generato automaticamente il 12 janvier 2021.

\section{(c) $(1) \ominus$}

Studi Francesi è distribuita con Licenza Creative Commons Attribuzione - Non commerciale - Non opere derivate 4.0 Internazionale. 


\title{
Genèse et autofiction, sous la direction de Jean-Louis Jeannelle et Catherine Viollet
}

\author{
Gabriella Bosco
}

\section{NOTIZIA}

AA. VV., Genèse et autofiction, sous la direction de Jean-Louis JEANNELLE et Catherine VIOLLET, «Au cœur des textes», n. 6, Academia Bruylant, Louvain-la-Neuve, 2007, pp. 259.

1 Il volume miscellaneo a cura di Jean-Louis Jeannelle et Catherine Viollet lavora intorno e dentro alla nozione di autofiction considerata come genere narrativo nuovo, per la fusione d'istanze contraddittorie, entrato in scena nel 1977 (Fils, Doubrovsky). Termine ambiguo e imprendibile per le innumerevoli interpretazioni ch'esso autorizza e le realizzazioni anche antitetiche cui dà adito, quello di autofiction determina necessariamente una turbativa nel campo delle classificazioni per generi, soprattutto se il canone per le scritture che parlano in prima persona è individuato nel Pacte autobiographique di Philippe Lejeune, teorizzazione tanto giovane quando Serge Doubrovsky compì il gesto provocatore (il saggio di Lejeune uscì in prima edizione nel 1975), quanto - da subito - autorevole (Catherine viollet, Troubles dans le genre, pp. 7-13). La scommessa dei curatori consiste nel ricorrere alla critica genetica come strumento per affinare quella generica (dei generi) in fatto di autofiction. Il loro scopo, in altri termini, è di verificare in che misura l'analisi genetica permetta di capire, attraverso la specificità di modi di procedere diversi, i meccanismi delle interferenze e interazioni tra istanza personale e discorso romanzesco, e di cogliere, all'interno del processo della scrittura, la dialettica che combina indizi referenziali e finzionali.

2 Delle tre parti di cui si compone il volume, la prima - «Genèse d'une notion» - indaga le origini del termine. Jean-Louis Jeannelle tenta l'impresa ardua e rischiosa di fare ordine tra le carte, ripercorrendo le tappe di una vicenda ormai trentennale, individuando 
precise fasi evolutive e proponendo, ancora, un'interpretazione (Où en est la réflexion sur l'autofiction, pp. 17-37). A seguire, Isabelle GRELL (Pourquoi Serge Doubrovsky n'a pu éviter la notion d'autofiction, pp. 39-51) e Serge DouBRovsKY stesso (Les points sur les «i», pp. 53-65) riprendono in mano il mastodontico manoscritto di Fils per far luce con il senno di poi su quella che fu realmente la prima utilizzazione del termine, scomparsa nell'edizione a stampa. Una corposa seconda parte, «L'épreuve des manuscrits», propone una serie di verifiche testuali della nozione di autofiction, cominciando da un'ipotesi di retroattività della stessa. Così, Nathalie MAURIAC DYER la applica alla Recherche proustiana (pp. 69-87), Maryse VASSEVYÈRE al mentir-vrai di Louis Aragon (pp. 91-101), Pierre-Marie HÉRON al Journal du Voleur di Genet (pp. 105-122), Régis teTtAMANZI al Céline di Beaux draps (pp. 123-141), mentre Philippe LEJEUNE personalmente ritorna su Perec (Autobiographie et fiction, pp. 143-147), e Philippe GASPARINI studia il percorso evolutivo autofictionnel di Annie Ernaux da Se perdre a Passion simple (pp. 149-173).

3 Nella terza e ultima parte del volume, «Les aléas d'un genre», sono invece interpellati alcuni romanzieri contemporanei, tutti coinvolti anche nella teorizzazione della scrittura in prima persona, perché illustrino il loro personale rapporto con il concetto indagato. Sono Vincent ColonNA (Note sur une autofiction fantastique. Comment j'ai cru écrire "Ma vie transformiste", pp. 177-184), Philippe VILAIN (L'épreuve du référentiel, pp. 185-187), Catherine CUSSET (L'écriture de soi: un projet moraliste, pp. 197-209), Philippe FOREST (La vie est un roman, pp. 211-219), Camille LAURENS ((Se) dire et (s)'interdire, pp. 221-228) e Anne F. GARRETA (Autofiction: la Ford intérieure et le self roman, pp. 229-239).

4 Arricchiscono il volume numerose riproduzioni di pagine tratte dai manoscritti delle opere studiate, e una ricca e interessante bibliografia sull'autofiction a cura di Jean-Louis JEANNELLE (pp. 241-253). 